\title{
Italian version of the Laval Questionnaire: validity and reliability
}

- Roberto Accardi, RN, MSc, Fondazione IRCCS Ca' Granda Ospedale Maggiore Policlinico, Department of surgery, Milan, Italy

- Stefano Terzoni, RN, PhD, Tutor nurse, lecturer in Nursing, San Paolo bachelor school of Nursing, San Paolo teaching hospital, Milan, Italy

- Enrico Mozzi, MD, researcher in Surgery, University of Milan (Italy), Department of medical, surgical and transplantation pathophysiology

- Ezio Lattuada, MD, Chief medical officer, bariatric surgery unit, San Pio X hospital, Milan, Italy

- Emanuela Racaniello, RN, MSc, Fondazione IRCCS Ca' Granda Ospedale Maggiore Policlinico, Department of surgery, Milan, Italy

- Silvia Ronchi, RN, Department of Cardiology, Azienda Ospedaliera Ospedale Niguarda Ca' Granda, Milan, Italy

- Cristian Ricci, MSc, PhD, statistician, University of Lione (France)

- Anne Destrebecq, RN, MSc - Associate Professor of Nursing, University of Milan (Italy), Department of Biomedical Sciences for Health

Keywords: morbid obesity, questionnaire, quality of life, assessment, validation

Running title: Italian Laval Questionnaire

Contact Info: Roberto Accardi, RN, MSC, PhD. Email Roberto.accardi@policlinico.mi.it, phone +39

0281844038

Word count: 3056

Funding sources: none.

Conflict of interest:

Dr. Accardi has nothing to disclose.

Dr. Racaniello has nothing to disclose.

Dr. Ronchi has nothing to disclose.

Dr. Destrebecq has nothing to disclose.

Contributions: Dr. Accardi and Prof. Destrebecq conceived the study, Dr. Terzoni and Dr. Ricci performed the statistical analysis, Dr. Mozzi, Dr. Lattuada, Mrs. Ronchi, and Dr. Racaniello supervised the clinical content of the study and helped in data collection.

What is already known on this topic:

- Obesity impairs quality of life

- The Laval questionnaire measures quality of life in patients waiting for bariatric surgery, but is not validated into Italian

- several domains of quality of life need to be assessed in these patients

\section{What this paper adds:}

- translation and validation into Italian of the Laval questionnaire

- measure of quality of life domains in Italian obese patients in a major hospital

- concurrent data, collected through other validated scale for depression and quality of life. 


\section{ABSTRACT}

Objective: Morbid obesity is often complicated by the presence of depression and poor quality of life. Bariatric surgery aims at improving quality of life of persons with obesity, as well as reducing mortality and medical risk factors. Quality of life assessment is important in clinical care planning, as well as in the evaluation of surgical outcomes. The Laval questionnaire has been specifically developed for patients with morbid obesity, but has never been validated into Italian; we aimed to produce an Italian version, in a population of patients scheduled for bariatric surgery.

Methods: multicentric observational study on a non-randomized sample of patients aged between 19 and 65 years, with morbid obesity and $\mathrm{BMI} \geq 35$, candidates for bariatric surgery (gastric banding or gastric bypass). Cronbach's alpha and factor analysis were used to assess internal consistency and structure.

Results: 163 patients enrolled, mean BMI of $42.8 \pm 7.5 \mathrm{~kg} / \mathrm{m} 2$ (range 31-70). Excellent consistency (alpha>.90) and concurrent validity with the Orwell's questionnaire (rho=-.78, p<.001). Factor analysis confirmed the six domains of the scale, all with good factor loadings (>.75).

Conclusions: the Italian version of the Laval questionnaire is valid and reliable for assessing quality of life in patients waiting for bariatric surgery.

\section{BACKGROUND}

Since the Seventies, the increase in chronic diseases incidence rates has been leading to the awareness that rarely are they curable (Pristed, Omar, \& Kroustrup, 2012). For this reason, attention has been shifting from "quantity" of life, expressed in terms of longevity, to quality of life. (Barcaccia et al., 2013) In 1995, the World Health Organization defined quality of life as the "individuals' perception of their position in life in the context of culture and value systems in which they live, and in relation to their goals, expectations, standards and concerns"; ("The World Health Organization Quality of Life assessment (WHOQOL)," 1995) therefore, it is a dynamic, complex and highly subjective concept, with both positive and negative aspects and includes physical, psychological and social dimensions, expression of one's health. (Stolzenberger, Meaney, Marteka, Korpak, \& Morello, 2013) 
Obesity, the main chronic emerging disease in the last decades, (Haidar \& Cosman, 2011) is a complex, multifactorial condition that can be related to emotional, environmental and genetic situations; it is defined by the presence of a BMI greater than $30 \mathrm{~kg} / \mathrm{m}^{2}$. (Camden, S., 2009)(Huang, Hsu, Pan, Huang, \& Chi, 2011)(Therrien et al., 2011)

Morbid obesity is often complicated by the presence of depression and compromised quality of life. (Huang et al., 2011)(Therrien et al., 2011)

The decrease in the perception of health-related quality of life is especially evident in those patients with obesity who seek to undergo surgical treatment for weight loss. (Busetto, L. et al., 2012)(Bentley et al., 2011) Bariatric surgery is aimed at improving quality of life of persons with obesity, as well as reducing mortality and medical risk factors (Nelbom, Naver, Ladelund, \& Hornnes, 2010). Quality of life assessment in patients with obesity is important in clinical care planning, as well as in the evaluation of surgical outcomes. A number of generic tools for assessing quality of life have been developed and validated in literature in order to perform the assessment in clinical setting. Nevertheless, the researchers of the Laval Hospital, in Canada, pointed out a need for a specific questionnaire for patients with morbid obese to assess the results of gastric bandage and gastric bypass: therefore, they created a tool sensitive to changes induced by the treatment, specifically developed for patients with morbid obesity, which can be useful in both research and clinical practice. (Therrien et al., 2011)

The Laval questionnaire has never been validated into Italian; the aim of this study is to produce and test an Italian version of such tool, in a population of Italian patients with obesity scheduled for bariatric surgery.

\section{MATERIALS AND METHODS}

This multicentre validation study was conducted in Italian, in the years 2013 and 2014, at the Fondazione IRCCS Ospedale Maggiore Policlinico of Milan and the Casa di Cura San Pio X in Milan, two Italian centers of bariatric surgery. We included in the study, patients aged between 19 and 65 years, with morbid obesity and $\mathrm{BMI} \geq 35$, candidates for bariatric surgery (gastric banding or gastric bypass) in accordance with the international guidelines and waiting for it. They were included if provided the informed consent. The presence of comorbidity was not a criterion for exclusion from the study. They were instead excluded 
patients with impaired cognitive status or not candidates for bariatric surgery. The recruitment of patients for the study was done at the time of the first visit with the bariatric surgeon, when took place the first administration of the tools.

\section{Validation study}

Initially (Time 0) the Laval Questionnaire and 4 other validated instruments were administered to all patients.

The Laval Questionnaire, originally developed in Canada and written in French, includes 44 items divided into six domains: Symptoms; Activity / mobility; Personal hygiene / clothing; Emotions; Social interaction and Sexual life. Each domain is scored on a 7-point Likert scale, higher scores meaning better quality of life. Patients are asked to indicate how their obesity has affected their lives in the last 4 weeks. The administration takes on average 10 minutes. (Therrien et al., 2011) In this study we used the Italian version, created on the basis of a process of back-translation.

The Short Form SF-36 is a self-administered questionnaire (Fontaine et al., 1999) aimed at assessing 8 physical and psychological domains. For each of the domains, the scores are linearly transformed into a scale from 0 to 100. Higher scores indicate better quality of life. (Pilone et al., 2012)(Lund et al., 2011) The 8 subscales form generate two general health summaries: the physical and mental component scores. (Pilone et al., 2012)(Lund et al., 2011) For all these items, subjects are required to respond considering their experience in the previous 4 weeks. (Lerdal et al., 2011) The SF-36 questionnaire has adequate psychometric properties, including good construct validity, high internal consistency and high test-retest stability. (Fontaine et al., 1999)

The Obesity Related Well-Being is a self-report measure of quality of life related to obesity, which has been developed on the the basis of patients with obesity and health professionals' accounts of about the experience of obese subjects themselves.(Silva, Pais-Ribeiro, \& Cardoso, 2008)(Mannucci et al., 1999) The questionnaire consists of 18 items, each of which is divided into two questions: the first is related to the importance (occurrence) that the person attaches to a symptom and the second refers to the importance of subjective impairment of physical or mental well-being experienced by the person in his personal life (relevance). The items are conceptually divided into 3 different areas: symptoms, discomfort and impact. 
The total score is obtained from the sum of the scores of the individual items, calculated as the product of occurrence and relevance. Higher scores indicate a worse quality of life. (Silva et al., 2008)(Mannucci et al., 1999)(Duval, Marceau, Pérusse, \& Lacasse, 2006)(Lo Coco, G., Salerno, L., Gullo, S., \& lacoponelli, L., 2009)

The Beck Depression Inventory is a tool composed by 21 items which was developed specifically to identify depression. It was used as an assessment tool to monitor response to therapy in clinical trials and is the most widely used measure for the assessment of depressive symptoms in the context of bariatric surgery. The scores can range from 0 to 63 with a higher score that represents a greater impairment of the symptoms of depression. (Therrien et al., 2011)(Sarwer, Fabricatore, Eisenberg, Sywulak, \& Wadden, 2008)

The Rosenberg Self-Esteem Scale is based on a phenomenological conception of self-esteem: (MartínAlbo, Núñiez, Navarro, \& Grijalvo, 2007) is a widely used scale, it is constituted of 10 items that relate to self-respect and self-acceptance and requiring a response on a 4-point Likert scale. (Lerdal et al., 2011)(Martín-Albo et al., 2007) Five items are positively worded and five negatively. (Martín-Albo et al., 2007)

After two weeks (Time 1), considering the stability from the clinical point of view in this time period and prior to any intervention, we proceeded to a second administration of all selected instruments, to evaluated the test-retest reliability of the Laval Questionnaire. The subjects remained unaware of the answers given in the previous compilation.

\section{Statistical analysis}

Cronbach's alpha coefficient was calculated to assess internal consistency (Cronbach, 1951). Factor analysis with non-ortogonal Promax rotation was used to verify the structure of the six sub-scales included in the original version of the questionnaire. Steven's criterion was used to retain relevant factors after rotation. (Stevens, 2009) Before conducting factor analysis, Kaiser-Meyer-Olkin's measure of sample adequacy was calculated (Norman, 2008) and Bartlett's test of sphericity (Bartlett, 1937) was performed. Test-retest stability was assessed by Wilcoxon's signed-rank test for paired data. (Wilcoxon, F., 1945) Inter-rater reliability was not assessed, as the Laval questionnaire is meant to be self-administered. The level of significance for all tests was set at .05. All calculations were performed with SAS 9 for Windows (SAS Inc., Cary, NY, USA). 


\section{RESULTS}

163 patients were enrolled, according to the inclusion criteria ( 36 males, 127 females) aged $43 \pm 12$, with mean BMI of $42.8 \pm 7.5 \mathrm{~kg} / \mathrm{m}^{2}$ (range 31-70). Most patients were Italian ( $\left.\mathrm{n}=150\right)$. One patient was illiterate, 8 had primary school licence, 61 had secondary licence, 76 had high school degree, and 17 had graduated from university. Out of 163 participants, 1 was student (.61\%), 24 were housewife $(14,72 \%), 7$ retired (4,29\%), 24 unemployed (14,72\%), 107 office worker $(65,66 \%)$.

As regards comorbidities, 82 had gastric pyrosis (50.31\%), 75 had hypertension $(46.01 \%)$, 53 had osteoatrhitis (32.52\%), 47 had hypercholesterolemia (29.01\%), 43 had nocturnal apneas (26.38\%), 36 had diabetes (22.09\%), 27 had urinary incontinence (16.56\%), and 24 had venous ulcers (14.72\%). None of the patients had all comorbidities; 28 had no comorbidities at all. 101 had two or more, 67 had 3 or more.

\section{Quality-of-life, self-esteem, and depression}

In the physical domain of the SF-36 questionnaire, the patients had a median score of 38.5 , IQR=[31.4;47.7], indicating poor outcomes in the physical dimensions of quality of life. The mental components had a median score of $41.9, I Q R=[32.7 ; 50.9]$, still corresponding to low levels of quality of life.

The median score in the Rosenberg self-esteem questionnaire (psychological wellbeing) was 18, $\operatorname{IQR}=[14 ; 23]$, indicating normal levels of self-esteem; however, 42 patients had Rosenberg scores below 15, indicating low self-esteem.

According to the results of the Beck Depression Inventory, 80 patients had no signs of depression; 31, 21, and 31 participants had low, moderate, and high levels of depression respectively.

The Orwell questionnaire had a median score of 149 , IQR=[115;191] out of a possible range between 18 and 288. In this questionnaire, the higher the scores represent a lower quality of life. Therefore, the median score obtained by our patients indicates poor quality of life in the domains investigated by the questionnaire.

The overall mean scores in each domain of the Laval questionnaire are reported in table 1. 


\section{Characteristics of the Laval questionnaire}

The Laval questionnaire showed excellent internal consistency, with high Cronbach's alpha coefficients (.93 and .94 respectively, during the assessment at baseline and after two weeks).

Because the present study also aimes to investigate correlation between the Laval questionnaire and the other tools, we assessed the internal consistency of the SF-36, Rosenberg, Beck Depression Inventory, and Orwell questionnaires as well, in order to verify if such tools were suitable for being used in our sample. All alpha coefficients were satisfactory $(.86, .87, .94$, and .92 respectively).

Kaiser-Meyer-Olkin's measure of sampling adequacy was excellent (.95) and the result of Bartlett's sphericity test was significant $(p<.0001)$. Therefore, we proceeded with factor analysis, which pointed out a single eigenvalue complying with Kaiser's criterion of being $>1$ (actual value: 4.29 ). The factor loadings of such eigenvalue, calculated by taking into account the six domains of the questionnaire, as identified by the original authors, were all retained, since they all satisfied Steven's criterion (5.152/sqrt(n-2), being " $\mathrm{n}$ " the sample size). This analysis pointed out that the factor loadings corresponding to the six domains, all were of great importance in the overall construct of the scale, thus confirming the strict logical process behind the assessment conducted with the Italian version of the Laval questionnaire in this kind of patients, as well as the adherence of the Italian version to the construct conceived by the original authors.

Table 2 reports the factor loadings.

----TABLE 2 HERE----

\section{Concurrent validity}

The Italian version of the Laval questionnaire showed strong and significant correlation with the Orwell scores (Spearman's rho=-.78, 95\% Cl: -.836 to $-.716 \mathrm{p}<.001$ ). Correlation was negative because high Laval scores indicate good quality of life, and vice versa for the Orwell questionnaire.

Correlations between the psychological domains of the Italian Laval tool and the Rosenberg total score were satisfactory $(.72,95 \% \mathrm{Cl}: .635$ to .785 and $.69,95 \% \mathrm{Cl}: .59$ to .76 respectively, $\mathrm{p}<.001$ in both calculations).

Correlations between all domains of the Italian Laval questionnaire and the total Beck Depression Inventory tool were satisfactory and highly significant (activity: rho $=-.61,95 \% \mathrm{Cl}:-0.69$ to -0.50 ; emotions: - 
$.75,95 \% \mathrm{Cl}:-0.81$ to -0.67 ; social interactions: $-.69,95 \% \mathrm{Cl}:-0.76$ to -0.59 ; hygiene: $-.60,95 \% \mathrm{Cl}:-0.69$ to 0.48; symptoms: $-.63,95 \% \mathrm{Cl}:-0.72$ to -0.53 ; sexual life: $-.57,95 \% \mathrm{Cl}:-0.67$ to -0.46 ; $\mathrm{p}<.001$ for all calculations).

Correlation with the SF-36 scores was satisfactory, in both physical and mental domains. All correlations were highly significant $(p<.001)$. The mental domain of the SF-36 was correlated with the Laval domains "emotions" (Spearman's rho=.66, 95\% Cl: 0.56 to 0.74$)$, "sexual life" (.51, 95\% Cl: 0.39 to 0.62$)$ and "social interactions (.57, $95 \% \mathrm{Cl}: 0.45$ to .66$)$. The physical domain was correlated with "activity" (.62, 95\% Cl: .52 to .71$)$, "hygiene" (.54, $95 \% \mathrm{Cl} . .42$ to .64$)$ and "symptoms" (.63, $95 \% \mathrm{Cl}$ : .53 to .72$)$. The correlation coefficients, although not very high, are statistically significant.

\section{----TABLE 3 HERE----}

\section{DISCUSSION}

The WHO reports that 312 million people worldwide are obese; (Haidar \& Cosman, 2011) recent estimates conducted on Italian reality show that is affected about $10 \%$ of the adult population. (Istat (Istituto Nazionale di Statistica), n.d.) When the BMI is greater than $40 \mathrm{~kg} / \mathrm{m}^{2}$, the condition is defined as "morbid obesity", which is associated with an increase in a number of physical health problems and is often complicated by the presence of depression and compromised quality of life. (Camden, S., 2009)(Huang et al., 2011)(Therrien et al., 2011) Several studies confirm the existence of negative association between BMI and quality of life. (Huang et al., 2011)(Busetto, L. et al., 2012)(Bentley et al., 2011)(Fontaine \& Barofsky, 2001) On the contrary, weight loss, improves quality of life (4) and substantially reduces the risk of developing comorbilities. (Dixon \& O’Brien, 2002)

The treatment of choice for weight loss in morbid obesity is bariatric surgery that can be offered to patients that:

- Have a $\mathrm{BMI}>40 \mathrm{~kg} / \mathrm{m}^{2}$ and not coexist a high surgical risk, or

- Have a BMI $\geq 35 \mathrm{~kg} / \mathrm{m}^{2}$ with obesity-related comorbilities. (Mechanick et al., 2013)

To evaluate changes in quality of life, generic scales such as the Short-Form 36 are often used in different study: (15) they can be used in a variety of different medical conditions, but are not suitable to assess the potential issues regarding specific health problems such as obesity. (Fontaine \& Barofsky, 2001) 
Specific tools for a given disease are more sensitive to changes occurring during surgical treatments of obesity, because they use specific items to inquire specific aspects of quality of life. (R L Kolotkin, Meter, \& Williams, 2001)(Ronette L Kolotkin \& Crosby, 2002)

In Italy there is a need for a specific questionnaire for patients undergoing bariatric surgery: previous studies carried out by the Italian Group for Lap-Band about quality of life of patients with obesity have used the abovementioned generic SF-36. (Busetto, L. et al., 2012)(Pilone et al., 2012) The only specific questionnaire developed in Italian is the Obesity-Related Well-Being Scale (ORWELL 97), including 18 items which explores only the physical dimension of quality of life with symptoms related to BMI, without focusing on the psychosocial dimensions. (R L Kolotkin et al., 2001)

The overall purpose of this study was to assess the validity and reliability of the Italian version of the Laval Questionnaire for the assessment of HRQOL in patients with obesity who undergo bariatric surgery.

The reliability and internal consistency of the new questionnaire Laval in the Italian version were excellent, both at time 0 to time 1, with Cronbach's alpha values very similar to those obtained during validation of the original Canadian instrument.

We used factory analysis to identify complex interrelationships among items and group items that are part of similar concept in different tools: the results showed a medium-high relation between each construct of Laval and the same constructs identified by the items of the other questionnaires, except for the component "sexual life", for which the relationship were slightly weaker.

The correlation of the domain "emotions" of Laval Questionnaire with the Beck Depression Inventory is moderate and almost comparable to that obtained from the Canadian version.

As regards the SF-36 physical and mental domains were related respectively to different domains of Laval: the physical domain was related to "activities", "hygiene" and "symptoms", the domain mental "emotion", "sexual life "and" social interaction". The areas of Laval are properly distributed and related to the different domains of the SF-36. Although correlation was moderate, the results were satisfactory: it should be taken into account that the SF-36 is a generic measure of quality of life, whereas the Laval tool is more specific. This might partially justify the values of the correlation coefficient. Generic tools in fact are less likely to detect change in quality of life than disease-specific questionnaires which focus on specific areas of quality 
of life. As a consequence, generic questionnaires are usually less sensitive to change than disease-specific instruments, a situation that was also observed in a Canadian validation study. (Therrien et al., 2011)

In contrast to the findings in the validation study of the original instrument for which the correlation coefficient was low, the psychological domain of the Italian version presented a good correlation with the results of the Rosenberg Self-Esteem Scale, thus highlighting that the Italian version has a good ability to assess the mental dimension.

Finally, we analysed the correlation with the more specific questionnaire used in the Italian reality, the ORWELL-97: it has proved very satisfactory. The Laval appears therefore more similar and more correlated to the specific measures for people suffering from morbid obesity than generic measures, such as the SF36.

As regards depression, assessed through the Beck Depression Inventory, our results show that more than $50 \%$ of subjects in the sample presented symptoms of depression a certain level (low, moderate or high). The same occurred with regard to self-esteem, with 42 of 80 subjects with unsatisfactory self-esteem, evaluated with the Rosemberg Self-Esteem Scale. These results agree with the findings from the literature: people suffering from morbid obesity, especially if looking for a surgical therapy, have an impairment of the psychological component of HRQoL. (Cameron et al., 2012)(Nelbom et al., 2010) They refer in fact very often low levels of self-esteem, high levels of dissatisfaction with their bodies and depression related to the weight; (Nelbom et al., 2010) these issues are going to affect negatively the functionality of psychological subjects, also causing role limitations due to emotional problems. The impairment of psycho-emotional dimension of the HRQoL is also linked to the perception of discrimination or derision that individuals with obesity often live and perceive. (Huang et al., 2011) The stigma and prejudice that are often experienced and suffered by the subject with obesity appear to be associated with a lower quality of life and with more symptoms of depression. (van Hout, Verschure, \& van Heck, 2005)(Kent, 2007)(Sarwer et al., 2008)

\section{CONCLUSION}

The results of this study support the validity and reliability of the Italian version of the Laval Questionnaire for the assessment of HRQOL in patients with obesity who undergo bariatric surgery. This tool has a high 
relevance of the questions with respect to the construct investigated, the HRQoL, and has good internal consistency and high accuracy.

The assessment of QoL in patients with morbid obesity who await the surgical procedure is important because the improvement of $\mathrm{HRQoL}$ is one of the primary purposes of bariatric surgery: an improvement in HRQoL reported by the patient represents a rate of success of surgery. In addition, the HRQoL as subjectively reported by patients before the intervention can provide information about the expected outcome of treatment in terms of weight loss: it is shown that subjects who preoperatively were more dissatisfied with their HRQoL, are the ones who get most benefit from surgery. (Pilone et al., 2012) Although different tools for the evaluation of HRQoL in the obese patient nowadays exist in Italian, none of these is specific for the use in the contexts of bariatric surgery: the Laval Questionnaire appears to be a very specific instrument for patients with morbid obesity who intend to undergo interventions of bariatric surgery (gastric bypass and gastric banding), which can be extremely useful in clinical contest.

A more extensive use of Laval Questionnaire would be useful, even in reality of central and southern Italy, to confirm the results here obtained. 


\section{REFERENCES}

Barcaccia, B., Esposito, G., Matarese, M., Bertolaso, M., Elvira, M., \& De Marinis, M. G. (2013). Defining Quality of Life: A Wild-Goose Chase? Europe's Journal of Psychology, 9(1), 185-203. http://doi.org/10.5964/ejop.v9i1.484

Bartlett, M. S. (1937). Properties of Sufficiency and Statistical Tests. Proceedings of the Royal Society A: Mathematical, Physical and Engineering Sciences, 160(901), 268-282. http://doi.org/10.1098/rspa.1937.0109

Bentley, T. G. K., Palta, M., Paulsen, A. J., Cherepanov, D., Dunham, N. C., Feeny, D., ... Fryback, D. G. (2011). Race and gender associations between obesity and nine health-related quality-of-life measures. Quality of Life Research, 20(5), 665-674. http://doi.org/10.1007/s11136-011-9878-7

Busetto, L., Pilone, V, Schettino, AM, Furbetta, N, Zappa, M., Di Maro, A, ... Mozzi, E. (2012). Determinants of health-related quality of life in morbid obese candidates to gastric banding. Eating and Weight Disorder: EWD, 17(2), e93-e100.

Camden, S. (2009). Obesity: An Emerging Concern for Patients and Nurses. OJIN: The Online Journal of Issues in Nursing, 14(1), Manuscript 1.

Cameron, A. J., Magliano, D. J., Dunstan, D. W., Zimmet, P. Z., Hesketh, K., Peeters, A., \& Shaw, J. E. (2012). A bi-directional relationship between obesity and health-related quality of life: evidence from the longitudinal AusDiab study. International Journal of Obesity, 36(2), 295-303. http://doi.org/10.1038/ijo.2011.103

Cronbach, L. J. (1951). Coefficient alpha and the internal structure of tests. Psychometrika, 16(3), 297-334. http://doi.org/10.1007/BF02310555

Dixon, J. B., \& O'Brien, P. E. (2002). Changes in comorbidities and improvements in quality of life after LAPBAND placement. American Journal of Surgery, 184(6B), 51S-54S.

Duval, K., Marceau, P., Pérusse, L., \& Lacasse, Y. (2006). An overview of obesity-specific quality of life questionnaires. Obesity Reviews, 7(4), 347-360. http://doi.org/10.1111/j.1467-789X.2006.00244.x

Fontaine, K. R., \& Barofsky, I. (2001). Obesity and health-related quality of life. Obesity Reviews: An Official Journal of the International Association for the Study of Obesity, 2(3), 173-182. 
Fontaine, K. R., Barofsky, I., Andersen, R. E., Bartlett, S. J., Wiersema, L., Cheskin, L. J., \& Franckowiak, S. C. (1999). Impact of weight loss on health-related quality of life. Quality of Life Research: An International Journal of Quality of Life Aspects of Treatment, Care and Rehabilitation, 8(3), 275277.

Haidar, Y., \& Cosman, B. (2011). Obesity Epidemiology. Clinics in Colon and Rectal Surgery, 24(04), 205-210. http://doi.org/10.1055/s-0031-1295684

Huang, C.-Y., Hsu, M.-C., Pan, K.-C., Huang, C.-K., \& Chi, S.-C. (2011). Early Health Status and Health-Related Quality of Life after Laparoscopic Gastric Bypass Surgery in Morbidly Obese Patients. Bariatric Nursing and Surgical Patient Care, 6(4), 193-200. http://doi.org/10.1089/bar.2011.9943

Istat (Istituto Nazionale di Statistica). (n.d.). Fumo, alcol, obesità: i fattori di rischio. Retrieved from http://noi-

italia2013.istat.it/index.php?id=7\&user_100ind_pi1\%5Bid_pagina\%5D=440\&cHash=54fe46c915f3d 2e8b3c43aeeb7db13d5

Kent, P. (2007). Lifestyle Changes Following Bariatric Surgery. Bariatric Nursing and Surgical Patient Care, 2(3), 209-214. http://doi.org/10.1089/bar.2007.9962

Kolotkin, R L, Meter, K., \& Williams, G. R. (2001). Quality of life and obesity. Obesity Reviews: An Official Journal of the International Association for the Study of Obesity, 2(4), 219-229.

Kolotkin, Ronette L, \& Crosby, R. D. (2002). Psychometric evaluation of the impact of weight on quality of life-lite questionnaire (IWQOL-lite) in a community sample. Quality of Life Research: An International Journal of Quality of Life Aspects of Treatment, Care and Rehabilitation, 11(2), 157171.

Lerdal, A., Andenæs, R., Bjørnsborg, E., Bonsaksen, T., Borge, L., Christiansen, B., ... Fagermoen, M. S. (2011). Personal factors associated with health-related quality of life in persons with morbid obesity on treatment waiting lists in Norway. Quality of Life Research, 20(8), 1187-1196. http://doi.org/10.1007/s11136-011-9865-z

Lo Coco, G., Salerno, L., Gullo, S., \& lacoponelli, L. (2009). Relazioni interpersonali, stati emotivi e autostima in soggetti obesi binge eaters. Rivista Di Psicologia Clinica, (1). 
Lund, R. S., Karlsen, T.-I., Hofs $\varnothing$, D., Fredheim, J. M., Røislien, J., Sandbu, R., \& Hjelmesæth, J. (2011). Employment Is Associated with the Health-Related Quality of Life of Morbidly Obese Persons. Obesity Surgery, 21(11), 1704-1709. http://doi.org/10.1007/s11695-010-0289-6

Mannucci, E., Ricca, V., Barciulli, E., Di Bernardo, M., Travaglini, R., Cabras, P. L., \& Rotella, C. M. (1999). Quality of life and overweight: the obesity related well-being (Orwell 97) questionnaire. Addictive Behaviors, 24(3), 345-357.

Martín-Albo, J., Núñiez, J. L., Navarro, J. G., \& Grijalvo, F. (2007). The Rosenberg Self-Esteem Scale: translation and validation in university students. The Spanish Journal of Psychology, 10(2), 458-467.

Mechanick, J. I., Youdim, A., Jones, D. B., Garvey, W. T., Hurley, D. L., McMahon, M. M., ... Brethauer, S. (2013). Clinical practice guidelines for the perioperative nutritional, metabolic, and nonsurgical support of the bariatric surgery patient-2013 update: Cosponsored by american association of clinical endocrinologists, The obesity society, and american society fo. Obesity, 21(S1), S1-S27. http://doi.org/10.1002/oby.20461

Nelbom, B., Naver, L., Ladelund, S., \& Hornnes, N. (2010). Patient Characteristics Associated with a Successful Weight Loss after Bariatric Surgery. Bariatric Nursing and Surgical Patient Care, 5(4), 313-319. http://doi.org/10.1089/bar.2010.9994

Norman, G. R. (2008). Biostatistics: the bare essentials (3rd ed). Shelton, Conn: People's Medical Pub. House.

Pilone, V., Mozzi, E., Schettino, A. M., Furbetta, F., Di Maro, A., Giardiello, C., ... Busetto, L. (2012). Improvement in health-related quality of life in first year after laparoscopic adjustable gastric banding. Surgery for Obesity and Related Diseases, 8(3), 260-268. http://doi.org/10.1016/j.soard.2011.12.012

Pristed, S. G., Omar, H. K., \& Kroustrup, J. P. (2012). Association Between Fulfilment of Expectations and Health-related Quality of Life after Gastric Bypass. Applied Research in Quality of Life. http://doi.org/10.1007/s11482-012-9175-9 
Sarwer, D. B., Fabricatore, A. N., Eisenberg, M. H., Sywulak, L. A., \& Wadden, T. A. (2008). Self-reported stigmatization among candidates for bariatric surgery. Obesity (Silver Spring, Md.), 16 Suppl 2, S7579. http://doi.org/10.1038/oby.2008.450

Silva, I. L., Pais-Ribeiro, J., \& Cardoso, H. (2008). Quality of Life and General Health Perception in Women with Obesity: Do Eating Patterns Make a Difference? Applied Research in Quality of Life, 3(2), 127136. http://doi.org/10.1007/s11482-008-9050-x

Stevens, J. (2009). Applied multivariate statistics for the social sciences (5th ed). New York: Routledge.

Stolzenberger, K. M., Meaney, C. A., Marteka, P., Korpak, S., \& Morello, K. (2013). Long-Term Quality of Life Following Bariatric Surgery: A Descriptive Study. Bariatric Surgical Patient Care, 8(1), 29-38. http://doi.org/10.1089/bari.2013.9996

The World Health Organization Quality of Life assessment (WHOQOL): position paper from the World Health Organization. (1995). Social Science \& Medicine (1982), 41(10), 1403-1409.

Therrien, F., Marceau, P., Turgeon, N., Biron, S., Richard, D., \& Lacasse, Y. (2011). The laval questionnaire: a new instrument to measure quality of life in morbid obesity. Health and Quality of Life Outcomes, 9, 66. http://doi.org/10.1186/1477-7525-9-66

Van Hout, G. C. M., Verschure, S. K. M., \& van Heck, G. L. (2005). Psychosocial predictors of success following bariatric surgery. Obesity Surgery, 15(4), 552-560. http://doi.org/10.1381/0960892053723484

Wilcoxon, F. (1945). Individual comparisons by ranking methods. Biometrics Bullettin, 1(6), 80-83. 
Table 1 - Mean scores in the Laval domains

\begin{tabular}{|l|l|}
\hline Domain & Mean(sd) \\
\hline Activity & $4.1(1.6)$ \\
\hline Symptoms & $4.0(1.3)$ \\
\hline Hygiene & $3.9(1.6)$ \\
\hline Emotions & $3.9(1.4)$ \\
\hline Social interactions & $4.6(1.6)$ \\
\hline Sexual life & $3.8(1.5)$ \\
\hline
\end{tabular}

Table 2 - Factor loadings in the Italian version of the Laval questionnaire

\begin{tabular}{|l|l|}
\hline Variable & Loading \\
\hline Activity & .88 \\
\hline Symptoms & .85 \\
\hline Hygiene & .86 \\
\hline Emotions & .88 \\
\hline Social interactions & .83 \\
\hline Sexual life & .76 \\
\hline
\end{tabular}


Table 3 - Confidence interval for Spearman's rank correlation between the LAVAL Questionnaire and related instruments

\begin{tabular}{|c|c|c|c|c|c|c|c|}
\hline \multicolumn{8}{|c|}{ Laval questionnaire domains } \\
\hline & $\begin{array}{l}\text { Laval total } \\
\text { scores }(95 \% \mathrm{Cl}) \text {, } \\
\text { p-value }\end{array}$ & $\begin{array}{l}\text { Symptoms } \\
(95 \% \mathrm{Cl}), p- \\
\text { value }\end{array}$ & $\begin{array}{l}\text { Activity/ } \\
\text { Mobility } \\
(95 \% \mathrm{Cl}), \\
\text { p-value }\end{array}$ & $\begin{array}{l}\text { Personal } \\
\text { hygiene/ } \\
\text { Clothing } \\
\text { (95\%Cl), } \\
\text { p-value }\end{array}$ & $\begin{array}{l}\text { Emotions } \\
(95 \% \mathrm{Cl}) \\
\text { p-value }\end{array}$ & $\begin{array}{l}\text { Social } \\
\text { interactions } \\
(95 \% \mathrm{Cl}), \\
\text { p-value }\end{array}$ & $\begin{array}{l}\text { Sexual life } \\
(95 \% \mathrm{Cl}), \\
\text { p-value }\end{array}$ \\
\hline $\begin{array}{l}\text { Orwell total } \\
\text { scores }\end{array}$ & $\begin{array}{l}-. .78[-.84 ; 0.72] \\
p<.001\end{array}$ & & & & & & \\
\hline $\begin{array}{l}\text { Rosenberg total } \\
\text { score }\end{array}$ & $\begin{array}{l}.67[.58 ; 0.75] \\
p<.001\end{array}$ & & & & $\begin{array}{l}.69[.64 \\
; .78] \\
p<.001\end{array}$ & $\begin{array}{l}.72 \\
C[.59 ; .76] \\
p<.001\end{array}$ & \\
\hline $\begin{array}{l}\text { Beck Depression } \\
\text { Inventory tool }\end{array}$ & $\begin{array}{l}-.74[-.81 ;-.67] \\
p<.001\end{array}$ & $\begin{array}{l}-.63 \quad[-.72 ;- \\
.53] p<.001\end{array}$ & $\begin{array}{l}.61[-.69 \\
t ;-.50] \\
p<.001\end{array}$ & $\begin{array}{l}-.60[-.69 \\
;-.49] \\
p<.001\end{array}$ & $\begin{array}{l}-.75[-.81 ;- \\
.67] p<.001\end{array}$ & $\begin{array}{l}-.69 \quad[-.76 ; \\
-.59] p<.001\end{array}$ & $\begin{array}{l}-.57 \quad[-.67 ; \\
-.46] p<.001\end{array}$ \\
\hline \multicolumn{8}{|l|}{ SF36 } \\
\hline MCS & $\begin{array}{l}.59[.48 ; .68] \\
p<.001\end{array}$ & & & & $\begin{array}{l}.66 \quad[.56 ; \\
.74] p<.001\end{array}$ & $\begin{array}{lr}.56 & {[.45 ;} \\
.66] & p<.001\end{array}$ & $\begin{array}{l}.51 \quad[39 ; \\
.62] p<.001\end{array}$ \\
\hline PCS & $\begin{array}{l}.51[.39 ; .62] \\
p<.001\end{array}$ & $\begin{array}{l}.63 \quad[.53 ; .72] \\
p<.001\end{array}$ & $\begin{array}{l}.62[.52 ; \\
.71] \\
p<.001\end{array}$ & $\begin{array}{l}.53[.42 ; \\
.64] \\
p<.001\end{array}$ & & & \\
\hline
\end{tabular}

